\title{
Processing, structure and thermal conductivity correlation in carbon fibre reinforced aluminium metal matrix composites
}

\author{
Alberto Torres Miranda ${ }^{\mathrm{a}, *}$, Leandro Bolzoni ${ }^{\mathrm{b}}$, Nilam Barekar ${ }^{\mathrm{a}}$, Yan Huang ${ }^{\mathrm{a}}$, Jesik Shin ${ }^{\mathrm{c}}$, \\ Se-Hyun $\mathrm{Ko}^{\mathrm{c}}$, Brian John McKay ${ }^{\mathrm{a}}$ \\ a Brunel Centre for Advanced Solidification Technology, Brunel University London, Uxbridge UB8 3PH, UK \\ b School of Engineering, The University of Waikato, Hamilton 3240, New Zealand \\ c Korea Institute of Industrial Technology, Incheon, South Korea
}

\section{H I G H L I G H T S}

- $\mathrm{Al} /$ CFs composites TC increased by $19.6 \%$ using a novel combination of processing techniques (Rheocasting + ECAE).

- ECAE can be used to align fibres within the $\mathrm{Al}$ matrix and maximise the TC of the $\mathrm{Al} / \mathrm{CF}$ composites.

- It is the first time that this combination of processing has been demonstrated to improve TC.

- Theoretical models are in agreement with experimental findings.

\section{G R A P H I C A L A B S T R A C T}

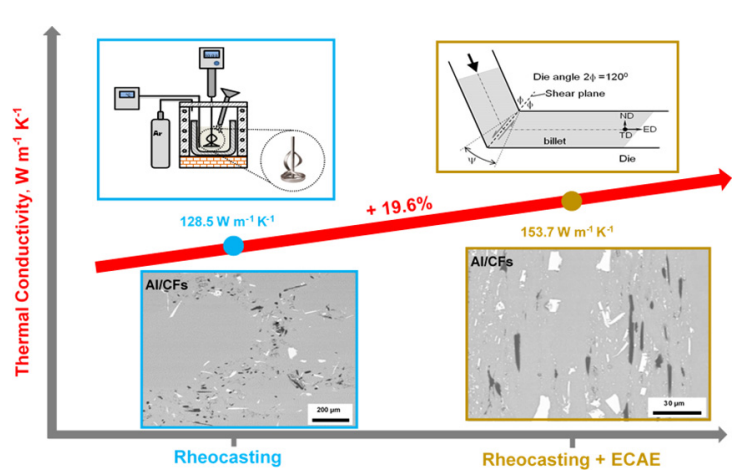

\begin{abstract}
A B S T R A C T
Al matrix composites reinforced with Cu-coated pitch-based carbon fibres (Al/Cu-CFs) were fabricated, using a novel combination of rheocasting and equal channel angular extrusion (ECAE) techniques, in order to exploit the thermal conductivity $(K)$ of the material. Rheocasting allowed the introduction and dispersion of Cu-CFs within the $\mathrm{Al}_{3} \mathrm{Mg}$ matrix. The subsequent ECAE processing reduced the porosity of the composites from 3 to $0.03 \%$ and induced a high degree of fibre alignment within the matrix, although considerable damage to the fibres occurred during this processing step. After 6 ECAE passes, in which the billet orientation remained constant, the composite with the highest degree of fibre alignment show a thermal conductivity $(K)$ improvement of $20 \%$ with respect to the rheocast composite. The improvement is due to porosity reduction, improved fibre alignment and forced intimate contact of clean CF surfaces with the matrix.
\end{abstract}

(c) 2018 Elsevier Ltd. All rights reserved.

Aluminium

Carbon fibres

Thermal properties

\footnotetext{
* Corresponding author.

E-mail address: alberto.miranda2@brunel.ac.uk (A.T. Miranda).
}

\section{Introduction}

In past years the rapid development of the electronic industry has greatly benefited society. Nevertheless, more recently, some highend technological applications have seen their advances limited by the inherent inability to find new materials capable of meeting industrial and consumer demands. One of the most challenging 
technological barriers that have hindered progress in electronics is the failure to remove excessive heat produced during the operation of equipment used in microelectronics and optoelectronics applications, such as microprocessors, power modules, light-emitting diodes (LEDs), plasma and liquid crystals displays (LCD) and thermoelectric coolers (TECs), to name but a few [1-3]. The amount of heat generated in electronic devices has been steadily increasing during the last few decades due to the miniaturization of components and the consumption of increasing electrical power in electronic circuits. This heat, if not efficiently removed, can cause catastrophic failures by overheating or deformation. Therefore, finding materials capable of achieving these functions, in extreme conditions (fast heating/cooling cycles, high humidity, etc.), is one of today's major challenges for this industry [1].

Traditional materials have serious deficiencies in meeting the requirements for thermal management, especially in terms of minimization of thermal stresses in electronics packaging. Traditional thermal management materials generally belong to the moderate thermal conductivity $(K)$ materials group, $K<300 \mathrm{~W} \mathrm{~m}^{-1} \mathrm{~K}^{-1}$; apart from Copper ( $\mathrm{Cu}, K=400 \mathrm{~W} \mathrm{~m}^{-1} \mathrm{~K}^{-1}$ ) which belongs to the high-thermal conductivity group, $300 \mathrm{~W} \mathrm{~m}^{-1} \mathrm{~K}^{-1} \leq K \leq 400 \mathrm{~W} \mathrm{~m}^{-1} \mathrm{~K}^{-1}$. Cu, the standard material for applications requiring high thermal conductivity, has a coefficient of thermal expansion ( $\mathrm{CTE}=17 \mathrm{ppm} \mathrm{K}^{-1}$ ) that is much larger than those of ceramics and semiconductor materials, giving rise to thermal stresses when packages are subjected to cyclic thermal loads. Aluminium (Al, $K=237 \mathrm{~W} \mathrm{~m}^{-1} \mathrm{~K}^{-1}$ ) has a lower thermal conductivity and larger CTE (23 ppm K${ }^{-1}$ ) than Cu but it is cheaper and lighter, making it a more attractive option. Moreover, $\mathrm{Al}$ has the potential to be applied as a heat sink for electronic devices when combined with high thermal conductivity reinforcements [2].

Carbon-based materials, such as pitch-based carbon fibres (CFs, $\left.1100 \mathrm{~W} \mathrm{~m}^{-1} \mathrm{~K}^{-1}\right)$, highly oriented pyrolytic graphite $\left(1700 \mathrm{~W} \mathrm{~m}^{-1} \mathrm{~K}^{-1}\right)$ and diamond $\left(2200 \mathrm{~W} \mathrm{~m}^{-1} \mathrm{~K}^{-1}\right)$ are already used to manufacture thermal management materials due to their good thermal conductivity and low CTE. Monolithic carbonaceous materials and composites reinforced with boron arsenide $\left(K>2000 \mathrm{~W} \mathrm{~m}^{-1} \mathrm{~K}^{-1}\right)$, natural graphite platelets $\left(K=3000 \mathrm{~W} \mathrm{~m}{ }^{-1} \mathrm{~K}^{-1}\right)$, graphene $(K$ $\left.\approx 5000 \mathrm{~W} \mathrm{~m}^{-1} \mathrm{~K}^{-1}\right)$, or carbon nanotubes $\left(K>6000 \mathrm{~W} \mathrm{~m}^{-1} \mathrm{~K}^{-1}\right.$, theoretical value) have the best potential to produce thermal management materials with ultra-high thermal conductivities $[4,5]$.

The limited number of scientific studies performed on the thermal conductivity of the MMCs, especially aluminium matrix composites (AMCs) reinforced with anisotropic carbonaceous materials such as carbon nanotubes [6], clearly demonstrates the undeveloped state of these materials to harness the potential high thermal properties of the composites. The main reason is the challenge to manufacture them, i.e. introduction, individual dispersion and alignment of the carbonaceous nanofillers [6]. Therefore, the aim of this work is to describe a molten metal manufacturing method to prepare AMCs reinforced with CFs. CFs share several properties with carbon nanotubes, such as chemistry, shape and thermal conductivity anisotropy, that are ideal to validate the processing route [6].

Specifically, rheocasting was used to produce the composites because it is one of the simplest, cost efficient processes available to produce particulate reinforced MMCs. Rheocasting distributes the fibres randomly within the matrix. To enhance conductivity it is necessary to align the fibres to harness their full potential. Equal channel angular extrusion (ECAE) was then considered as a post-processing technique to increase the structure and properties of the CF-reinforced AMCs. To date to the author's best knowledge, there is no published data on $\mathrm{Al} /$ $\mathrm{CF}$ composites produced via rheocasting followed by ECAE. The thermal conductivity of the composites was assessed using the laser flash technique and compared with various theoretical models that take into account fibre geometry, anisotropy and orientation. An improvement of $20 \%$ with respect to the as-cast composite was achieved in the ECAE composites [6].
Table 1

Nominal chemical composition of commercially pure Al (wt\%) BS 1490:1988.

\begin{tabular}{llllllllllll}
\hline & $\mathrm{Cu}$ & $\mathrm{Mg}$ & $\mathrm{Si}$ & $\mathrm{Fe}$ & $\mathrm{Mn}$ & $\mathrm{Ni}$ & $\mathrm{Zn}$ & $\mathrm{Pb}$ & $\mathrm{Sn}$ & $\mathrm{Al}$ & Others \\
\hline Max. & 0.03 & 0.03 & 0.30 & 0.40 & 0.03 & 0.03 & 0.07 & 0.03 & 0.03 & 99.5 & 0.50 \\
\hline
\end{tabular}

\section{Experimental techniques and procedures}

\subsection{Starting materials}

For the proposed AMCs, the matrix alloy selection is of major importance due to the fact it has to be suitable for semi-solid metal (SSM) processing via rheocasting, which requires an alloy with a large freezing range $\left(\Delta \mathrm{T}_{\mathrm{L}-\mathrm{S}}\right)$. In addition it should also be alloyed with an element that decreases the Al surface energy in order to facilitate wettability and incorporation of the fibres within the matrix. An Al-3wt\%Mg alloy (all compositions hereafter denoted as wt\%) produced by mixing commercially pure (CP) Al (LM0, BS 1490:1988) purchased from Norton $\mathrm{Al}$ (UK), with CP Mg purchased from Magontec (Germany) was used in this study. The nominal compositions of the raw materials are given in Tables 1 and 2.

Mesophase pitch-based, short CFs designated as Raheama R-A201 purchased from Teijin Limited (Japan) were the selected reinforcement. According to manufacturer's specifications, the CFs have an average diameter of $8 \mu \mathrm{m}$, length of $50 \mu \mathrm{m}$ and possess a thermal conductivity that ranges between 500 and $600 \mathrm{~W} \mathrm{~m}^{-1} \mathrm{~K}^{-1}$. The fibres were coated with $\mathrm{Cu}$ via electroless deposition at the Korean Institute of Industrial Technology (KITECH), Incheon, South Korea and, thus labelled Cu-CFs.

The diameter and length distribution of the fibres were obtained from the SEM images using the Image J 1.45s open source software. Five different micrographs (representative examples shown in Fig. 1) were used to obtain 60 diameter and length measurements. The fibres show a diameter size distribution between $5.48 \mu \mathrm{m}$ to $15.58 \mu \mathrm{m}$ with a mean diameter of $8.79 \pm 2.03 \mu \mathrm{m}$. The length of the CFs was found to vary from $28 \mu \mathrm{m}$ to $825.88 \mu \mathrm{m}$ with a mean length of $285.41 \pm 177.27 \mu \mathrm{m}$.

Fig. 1(a) and (b) show low and high magnification, secondary electron (SE) images of the as-received Cu-CFs, and the inset reveals the corresponding high energy dispersive spectrum from the characteristic Xrays detected from the image area, showing $C$ peaks from the CFs and $\mathrm{Cu}$ peaks from the coating. The characteristic well-aligned graphitic layers arranged almost parallel to the fibre axis of the mesophase pitch-based carbon fibres $[7,8]$ were confirmed by the low acceleration voltage In-lens high magnification image of the uncoated CFs (Fig. 1(c)).

The diameter and length of the $\mathrm{Cu}-\mathrm{CFs}$ given above, marginally differ from the values given by the manufacturer, $\mathrm{d}_{\mathrm{CFs}} \sim 8 \mu \mathrm{m}$ and $\mathrm{l}_{\mathrm{CFs}} \sim 50-200$ $\mu \mathrm{m}$. The increment in diameter $(\sim 0.8 \mu \mathrm{m})$ is explained by the Cu coating which can be seen from the backscatter electron (BSE) image of a fibre shown in Fig. 1(d).

\subsection{Composites processing}

The schematic representation of the rheocasting set-up used in this study is shown in Fig. 2. For each composite, $2.5 \mathrm{~kg}$ of Al-3Mg alloy was melted inside an A7 salamander clay graphite bonded crucible in a Carbolite resistance furnace at $700{ }^{\circ} \mathrm{C}$. The $\mathrm{Cu}$ coated carbon fibres were weighed and placed in an ELITE box furnace at $100{ }^{\circ} \mathrm{C}$ under an argon atmosphere for $2 \mathrm{~h}$ in order to remove moisture and avoid $\mathrm{Cu}$ oxidation. Once the alloy was molten, the crucible was transferred to a heating belt (a heating element wrapped around the crucible) at 550 ${ }^{\circ} \mathrm{C}$, and $\mathrm{Ar}$ gas was immediately purged to protect the melt from forming

Table 2

Nominal chemical composition of commercially pure Mg (wt\%) EN10204.

\begin{tabular}{lllllllll}
\hline & $\mathrm{Al}$ & $\mathrm{Zn}$ & $\mathrm{Mn}$ & $\mathrm{Si}$ & $\mathrm{Fe}$ & $\mathrm{Cu}$ & $\mathrm{Ni}$ & $\mathrm{ppm} \mathrm{Be}$ \\
\hline Max. & 0.04 & 0.00 & 0.02 & 0.013 & 0.002 & 0.001 & $<0.001$ & 1 \\
\hline
\end{tabular}



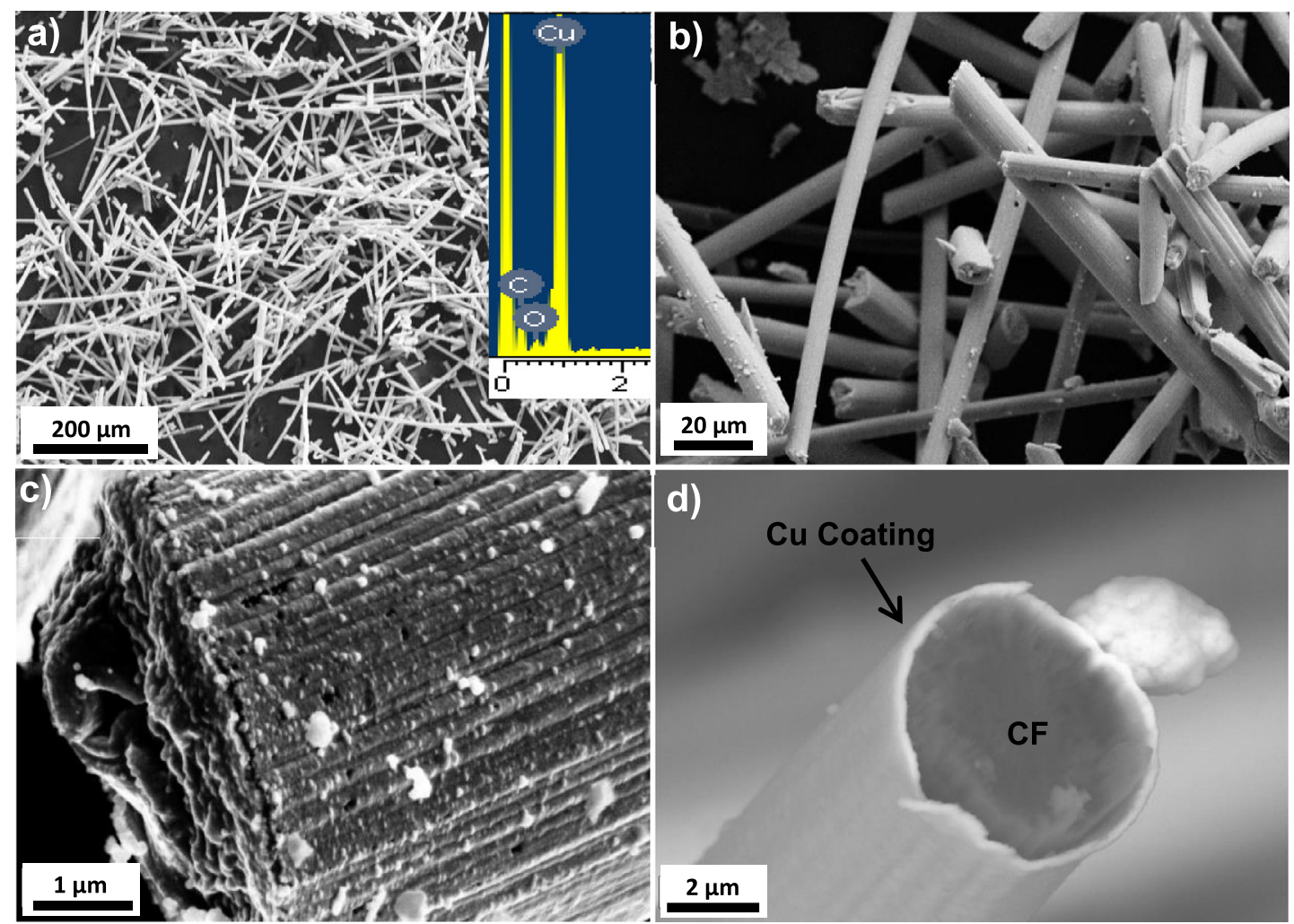

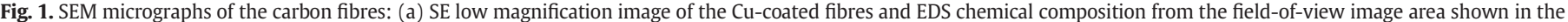

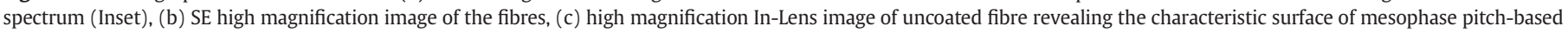
$\mathrm{CFs}$, and (d) high resolution BSE image of cross-section of a CF revealing a uniform $\mathrm{Cu}$ coating in bright contrast.

Al oxides. K-type thermocouples were then submerged in the melt to record the temperature.

In order to promote good fibre mixing and dispersion a laminar flow was created in the slurry [9]. For this, a high viscosity stainless steel mixing paddle (Berg model RR85 S, shown in Fig. 2(a), 85 mm in diameter and $400 \mathrm{~mm}$ in length) was coated with boron nitride to avoid Fe contamination of the melt and connected to a digital stirrer, IKA Eurostar 200. The mixing system was then positioned above the surface of the melt, where the paddle was preheated, whilst the melt temperature dropped. When the melt temperature was just above the liquidus temperature $\left(T_{L}=\right.$ $\sim 643{ }^{\circ} \mathrm{C}$ ), the paddle was inserted into the melt and placed $5 \mathrm{~mm}$ from the base of the crucible where it was rotated at $300 \mathrm{rpm}$.

The particle delivery system, made of steel tube $(450 \mathrm{~mm}$ in length and $15 \mathrm{~mm}$ in diameter), was positioned above the shallow vortex in the melt surface. Once the melt reached the semi-solid temperature $\left(\mathrm{T}_{\mathrm{SS}}\right)$ of $633^{\circ} \mathrm{C}(\sim 30 \%$ of solid fraction), the paddle speed was increased to $1200 \mathrm{rpm}$, and the introduction and mixing of the fibres in the SSM melt commenced. The whole system was covered with glass wool to reduce the heat loss. The fibres were introduced onto the melt surface at a rate of $15 \mathrm{~g} / \mathrm{min}$ and mixed for $10 \mathrm{~min}$ in total, after which the paddle was retracted from the melt and the crucible removed from the heating belt. A $5 \mathrm{~kg}$ ceramic block was then placed directly on the surface of the mushy melt to remove porosity created by the rotating paddle and was left to cool down in the crucible at room temperature.

Composite samples produced with different CF amounts $(0.5,1,1.5$ and $2 \mathrm{wt} \%$ ) will be referred as C0.5, C1, C1.5 and C2, respectively hereafter. Their final chemical composition was acquired by optical emission spectroscopy (OES). The data given in Table 3 clearly shows an increase in $\mathrm{Cu}$ content with increasing $\mathrm{CF}$ addition to the matrix.

ECAE is characterized by simple shear along the shear plane as shown in Fig. 2(b), which applies the highest possible relative material element spin among all types of deformation modes for a given strain and thus has the strongest impact on microstructural rotation to align with the extrusion direction. The billet's cross-section remains constant after ECAE and, if the billet orientation is unchanged between consecutive passes, strains are addible between passes of ECAE processing. This allows high strains to be applied on a single sample with an accumulative alignment effect, in addition to grain refinement. Plastic deformation via ECAE also helps to heal casting defects including the reduction of porosity. With the aim of improving the structure of the AMCs, the composite $\mathrm{C} 1.5$ was subjected to ECAE for fibre alignment and porosity reduction. Two $100 \times 5 \times 15 \mathrm{~mm}^{3}$ bars were post-processed via ECAE at $350{ }^{\circ} \mathrm{C}$ with ram speed of $\sim 0.75 \mathrm{~mm} / \mathrm{s}$ through a $2 \phi=120^{\circ}$ die using graphite lubricant. The process was repeated (4 to 6 passes) to apply an accumulative strain of $\sim 2.67$ and $\sim 4.0$ respectively.

\subsection{Composites characterisation}

Metallographic samples were produced using standard preparation techniques, P240, P600, P800 and P1200 grades of SiC grinding paper plus polishing ( $1 \mu \mathrm{m}$ KEMET diamond suspension followed by $0.04 \mu \mathrm{m}$ colloidal silica suspension). Microstructural analysis was performed using AxioVision $40 \mathrm{~V}$ 4.8.2.0 software on micrographs captured on a Zeiss Axio Scope.A1 AX10 optical microscope. For each sample, ten optical micrographs were taken at $5 \times$ magnification for porosity measurements and ten micrographs were taken at $20 \times$ magnification for fibre content quantification. If the phases are randomly dispersed, then it can be assumed that the volume fraction will be equal to the areal fraction. Thus, by comparing the area of a given phase to the overall area of the image, as illustrated in Fig. 3(a) and (b), the average volume fraction of the porosity/fibres can be determined. The real volume fraction of fibres, also designated in this work as "corrected" volume fraction $\left(v_{f}^{\text {corr }}\right)$, was determined by subtracting the average volume fraction of the porosity $(\varphi)$. These values were used while evaluating the effective thermal conductivity of the composites and denoted as effective thermal conductivity in the "corrected condition". 

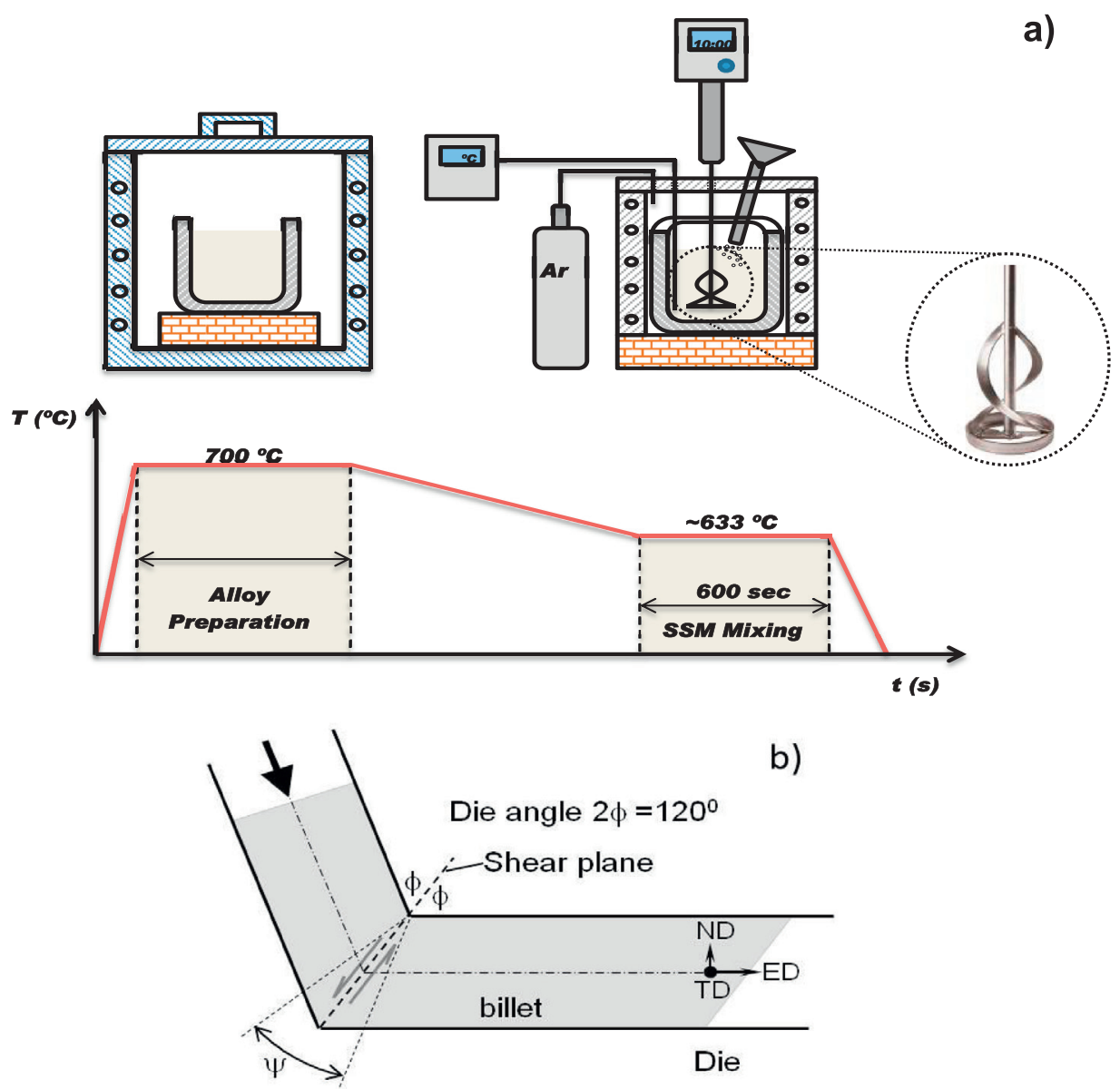

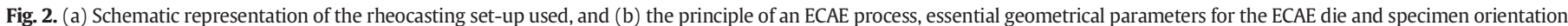
nominations.

Fibre distribution, agglomeration, final morphology and identification of potential reaction products formed at the $\mathrm{CF} /$ matrix interface were checked via SEM analysis using a field emission Zeiss Supra 35VP SEM.

The laser-flash, a transient technique that does not require physical contact between the test sample and the heater or detector [6], was employed to obtain the thermal conductivity of the composites. The thermal conductivity measurements were performed on a NETZSCH LFA 447 Nano Flash device. Each measurement required a set of 3 specimens, two specimens with dimensions $10 \times 10 \times 1 \mathrm{~mm}^{3}$ and one with dimensions of $3 \times 3 \times 1 \mathrm{~mm}^{3}$. Five measurements were taken for each $\mathrm{Al} / \mathrm{Cu}-\mathrm{CF}$ composite processed via rheocasting and rheocasting followed by ECAE.

\section{Results}

\subsection{Rheocasting}

Fig. 4 shows the microstructure evolution of the composites with increasing addition of CFs. The Al-3Mg sample without any CF addition has a globular grain structure which is a common characteristic of SSM processing (Fig. 4(a)). For the AMCs, the number of fibres (black features) in the matrix increase with increasing fibre weight fraction is clearly visible. The micrographs also reveal that the fibres are well distributed along the grain boundaries together with AlFe (grey features) intermetallics (Fig. 4(b-e)).

Fig. 4(f) shows a higher magnification micrograph of the $\mathrm{C} 2$ composite microstructure where the $\mathrm{CFs}$ are readily discernible and do not show any clear evidence of $\mathrm{Al}_{4} \mathrm{C}_{3}$ formation. Low processing temperatures and short mixing times used during rheocasting helped to minimize $\mathrm{Al}_{4} \mathrm{C}_{3}$ formation.

The effective fibre introduction into the melt is due to the high melt viscosity generated using carefully selected processing parameters as the viscosity depends on the solid fraction within the Al melt, the stirring shear rate and the time history $[10,11]$. It allowed the entrapment of the fibres, thus avoiding quick settling and rejection from the melt. Laminar flow mixing reoriented and redistributed the composite slurry by cutting, dicing, chopping and then restacking the sectioned material.

Table 3

$\mathrm{Al}-3 \mathrm{Mg} / \mathrm{Cu}-\mathrm{CFs}$ composites with corresponding respective average chemical composition (wt\%).

\begin{tabular}{|c|c|c|c|c|c|c|c|c|c|}
\hline \multirow[t]{2}{*}{ Sample } & \multirow[t]{2}{*}{ Designation } & \multicolumn{3}{|c|}{ CFs addition } & \multicolumn{5}{|c|}{ Measured composition (wt\%) } \\
\hline & & $w_{f}$ & $v_{f}$ & $\mathrm{Al}$ & $\mathrm{Si}$ & $\mathrm{Fe}$ & $\mathrm{Cu}$ & Mn & $\mathrm{Mg}$ \\
\hline $\mathrm{C} 0.5$ & $\mathrm{Al}-3 \mathrm{Mg} / 0.5 \mathrm{wt} \% \mathrm{Cu}-\mathrm{CFs}$ & 0.005 & 0.006 & 95 & 0.09 & 0.9 & 0.33 & 0.01 & 3.23 \\
\hline $\mathrm{C} 1$ & $\mathrm{Al}-3 \mathrm{Mg} / 1 \mathrm{wt} \% \mathrm{Cu}-\mathrm{CFs}$ & 0.01 & 0.012 & 94.3 & 0.1 & 1.04 & 0.78 & 0.01 & 3.40 \\
\hline C1.5 & $\mathrm{Al}-3 \mathrm{Mg} / 1.5 w \mathrm{t} \% \mathrm{Cu}-\mathrm{CFs}$ & 0.015 & 0.019 & 93.8 & 0.14 & 1.22 & 1.21 & 0.01 & 3.38 \\
\hline $\mathrm{C} 2$ & $\mathrm{Al}-3 \mathrm{Mg} / 2 \mathrm{wt} \% \mathrm{Cu}-\mathrm{CFs}$ & 0.02 & 0.025 & 93.3 & 0.08 & 0.95 & 2.04 & 0.01 & 3.33 \\
\hline
\end{tabular}




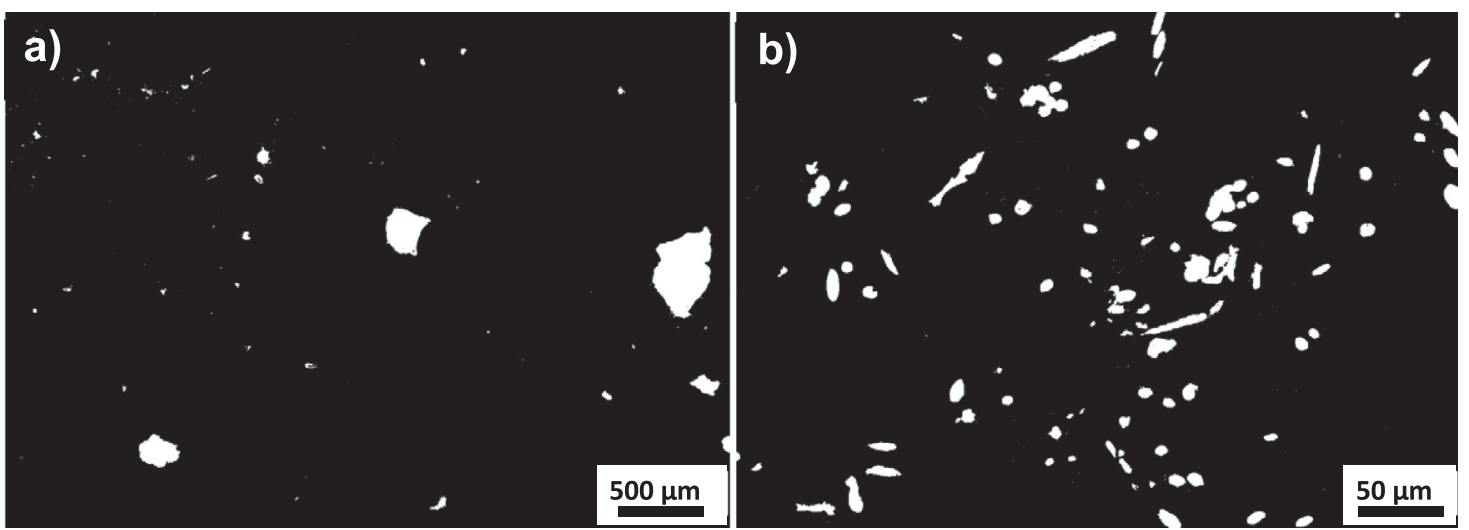

Fig. 3. Image analysis of $\mathrm{Al} / \mathrm{Cu}-\mathrm{CFs} \mathrm{C} 1.5$ composite using Image J software: (a) porosity and (b) CF content.

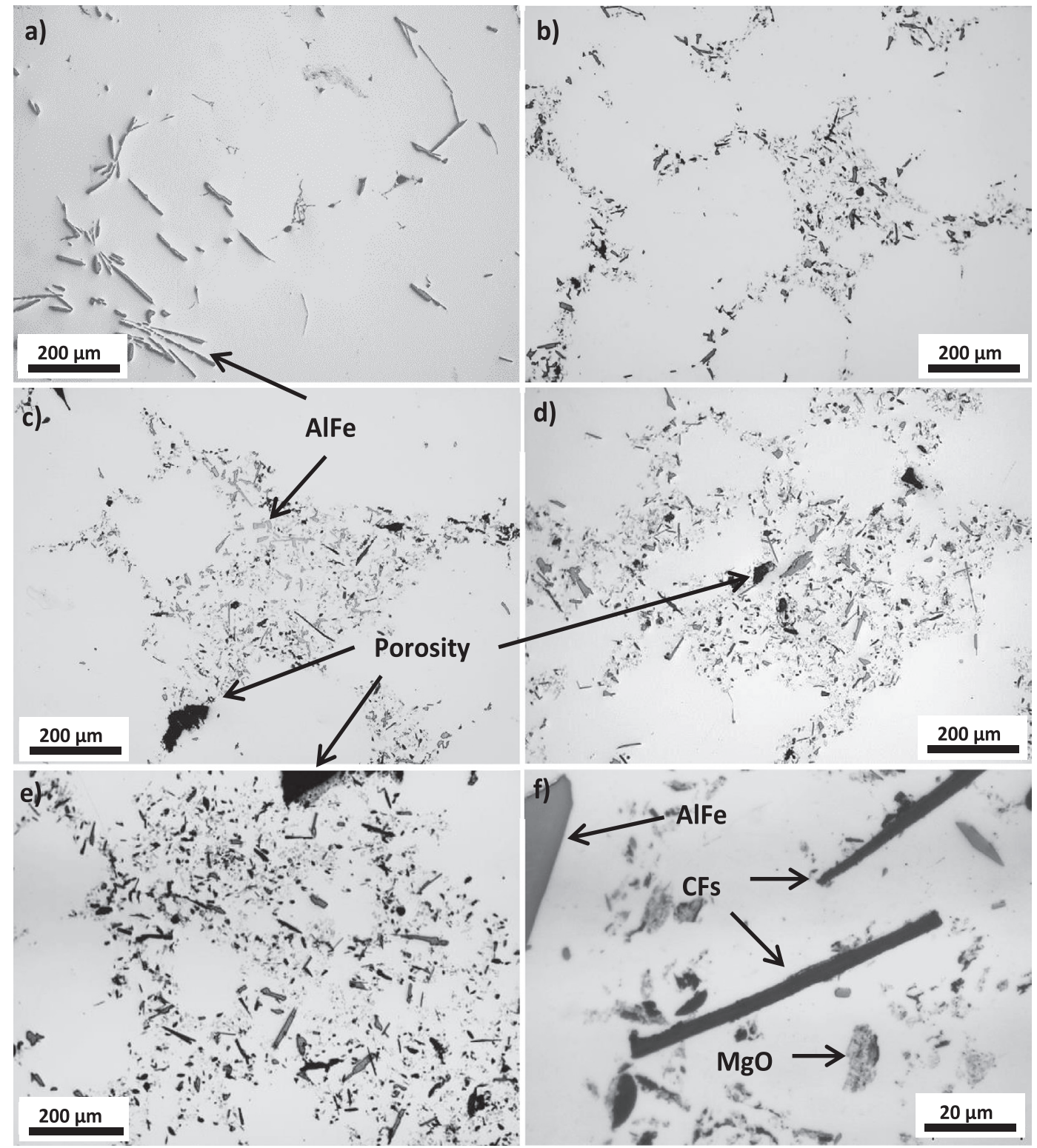

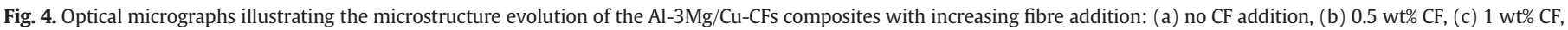
(d) $1.5 \mathrm{wt} \% \mathrm{CF}$, (e) $2 \mathrm{wt} \% \mathrm{CF}$, and (f) details of the CFs, Al-Fe phase and MgO film (formed after polishing surface preparation). 


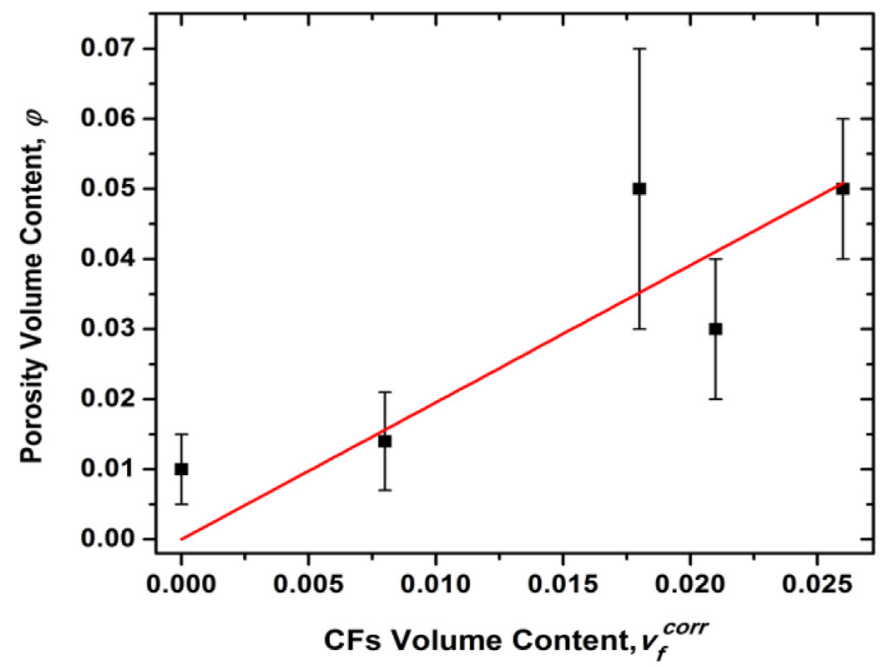

Fig. 5. Variation of the porosity volume fraction $(\varphi)$ with the real (or corrected) fibre $v_{f}^{\text {corr }}$ content.

The redistribution of the material increased the interfacial area allowing diffusion and consequently homogeneous dispersion of the fibres within the matrix [9].

The relationship between the porosity volume fraction $(\varphi)$ and $v_{f}^{\text {corr }}$ content presented in Fig. 5 reveals that the porosity increases linearly up to $5 \%$ with the increase in the fibre content. Porosity is typical of stir/vortex casting (mixing in the liquid state) or rheocasting techniques due to gas being dragged into the vortex from the surface of the melt. The gas enters into the slurry either in its molecular form or in the form of an envelope containing the reinforcing particles, therefore fibre content and porosity depend on one another [12]. The increase in melt viscosity due to an increase in fibre content may also contribute to increase porosity. These phenomena have previously been observed in studies involving the processing of AMCs with ceramic fibres [13-15].

CFs would generally be pushed away by the solidification front, thus forming large agglomerates that could eventually be pushed out of the melt, due the high surface energy difference between $\mathrm{Al}\left(\gamma_{A l}=\right.$ $\left.1.143 \mathrm{~J} \mathrm{~m}^{-2}\right)$ [16] and the CFs $\left(\gamma_{C F}=0.0459 \mathrm{~J} \mathrm{~m}^{-2}\right)$ [17]). In this study, the successful embedment and dispersion of the CFs into the $\mathrm{Al}$ matrix was also favoured by the presence of $\mathrm{Mg}$ and the $\mathrm{Cu}$ coating. Specifically, $\mathrm{Mg}$ sharply reduces the surface tension of Al and, therefore, improves the wettability between $\mathrm{Al}$ and the CFs. Furthermore, the $\mathrm{Cu}$ coating applied on the fibres (Fig. 1(d)) promotes wettability and interfacial bonding between fibres and the $\mathrm{Al}$ as $\mathrm{Cu}$ has much similar surface energy ( $\gamma_{C u}=1.825 \mathrm{~J} \mathrm{~m}^{-2}$ [16]) to that of Al. This is observed in Fig. 6 where good bonding between the fibres and surrounding Al matrix occurs.

The study of the cross-section of a CF embedded in the $\mathrm{Al}$ matrix (Fig. 6(b)), and the respective EDS elemental maps, reveals that the improvement in wetting of the CFs with the Al melt could be predominantly driven by the reaction of the $\mathrm{Mg}$ (Fig. 6(d)) from the matrix with the $\mathrm{O}$ (Fig. 6(e)) present at the surface of the fibre. Mg was found to react with the $\mathrm{CuO}$ and form $\mathrm{MgO}$ thereby forcing $\mathrm{Cu}$ to diffuse away from the fibre; however, in some cases small traces of $\mathrm{Cu}$ are still found around the fibre (Fig. 6(f)). Mg is a strong oxidiser and thus when an oxygen-containing surface, in this case the CuO layer present
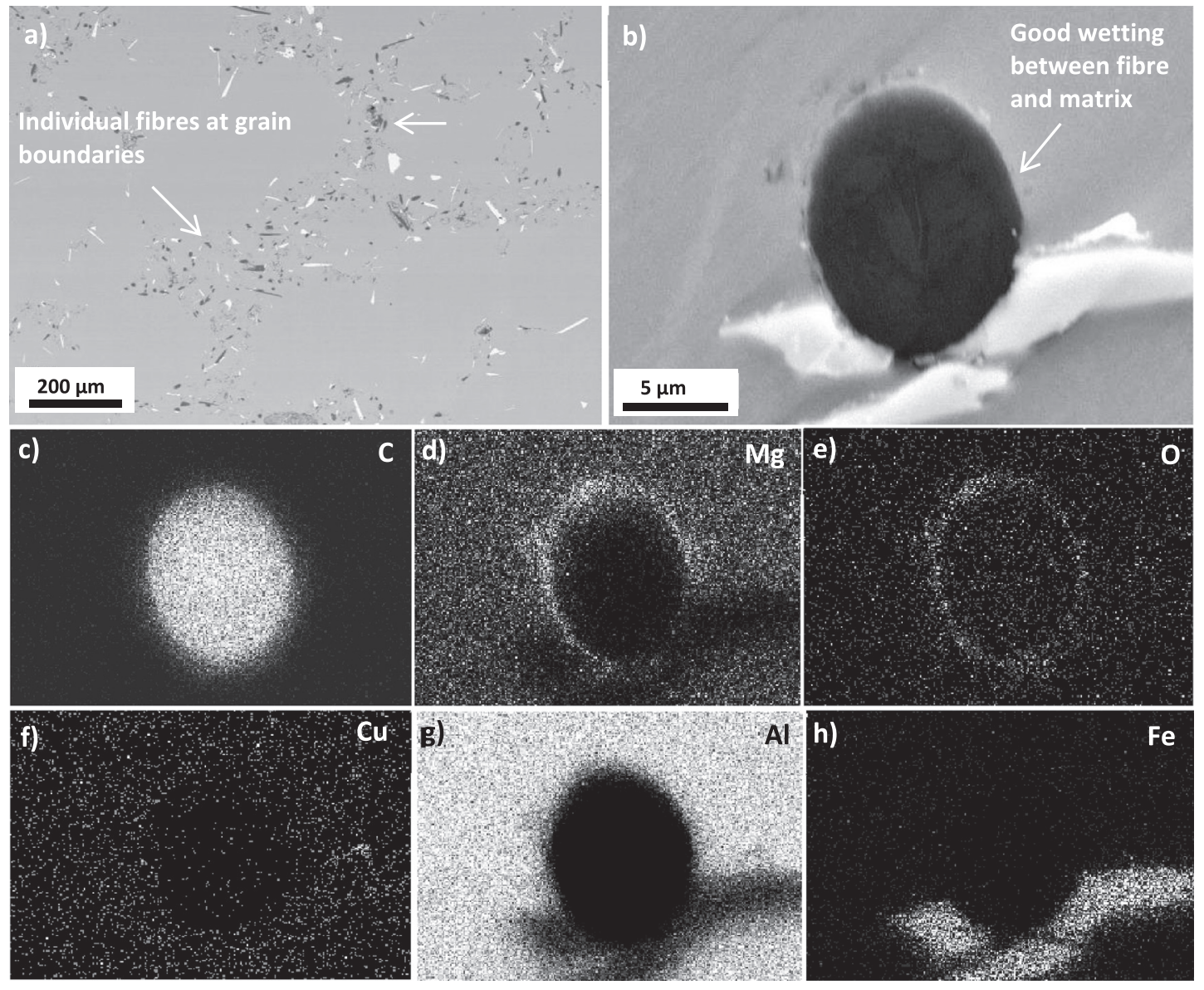

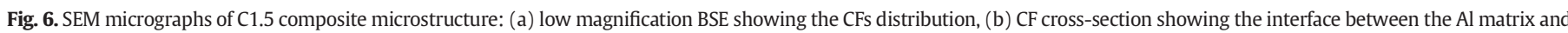
the CF and the respective EDS elemental map for: (c) C, (d) $\mathrm{Mg}$, (e) O, (f) $\mathrm{Cu}$, (g) $\mathrm{Al}$, and (h) Fe. 


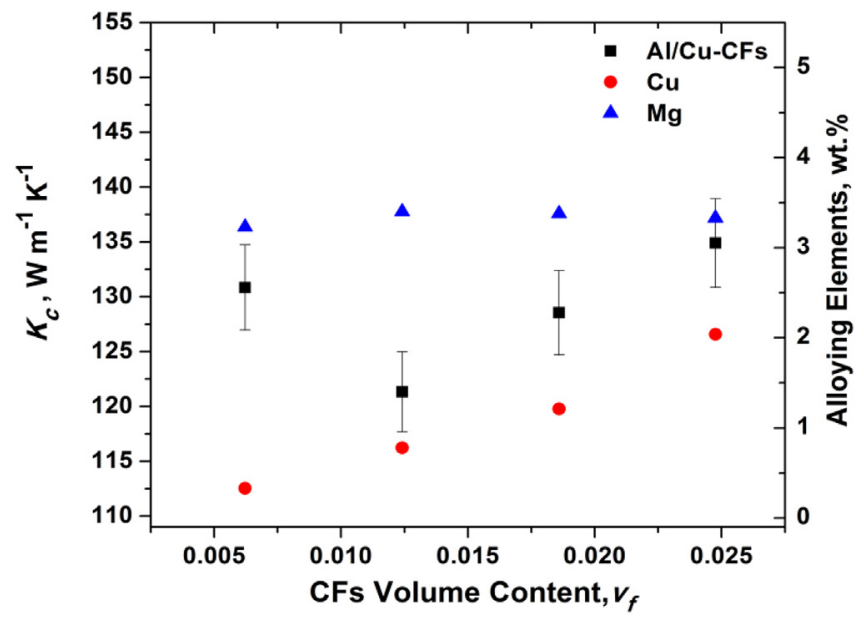

Fig. 7. Thermal conductivity, $\mathrm{Cu}$ and $\mathrm{Mg}$ contents of the $\mathrm{Al}-3 \mathrm{Mg} / \mathrm{Cu}-\mathrm{CFs}$ composite produced via rheocasting versus CFs volume content $\left(v_{f}\right)$.

in the coating, comes into contact with the melt is reduced by the $\mathrm{Mg}$, resulting in the formation $\mathrm{Mg}-\mathrm{O}$ based compound [18]. The study of the interface shows no evidence of carbon reaction products $\left(\mathrm{Al}_{4} \mathrm{C}_{3}\right)$ and confirms that the CFs are primarily located at the $\alpha$-Al grain boundaries and in some cases associated with the AlFe intermetallic possibly inducing the nucleation of the secondary phases (Fig. 6(h)).

The variation of the thermal conductivity with the CFs volume fraction $\left(v_{f}\right)$ content of the rheocast composites (Fig. 7) shows that the lowest value $\left(K_{c, C 1}=121.3 \pm 3.6 \mathrm{~W} \mathrm{~m}^{-1} \mathrm{~K}^{-1}\right)$ was reached when adding $1 \mathrm{wt} \%\left(v_{f}=0.012\right)$ CFs to the Al-3Mg matrix. For higher fibre addition contents, the CFs started to counteract the detrimental effect of $\mathrm{Cu}$ on thermal conductivity as observed for the $\mathrm{C} 1.5(1.5 \mathrm{wt} \%)$ composite $\left(v_{f}\right.$ $=0.019$ ) with $K_{c, C 1.5}=128.5 \pm 3.9 \mathrm{~W} \mathrm{~m}^{-1} \mathrm{~K}^{-1}$. The highest thermal conductivity $\left(K_{c, c 2}=134.9 \pm 4.1 \mathrm{~W} \mathrm{~m}^{-1} \mathrm{~K}^{-1}\right)$ was observed for the maximum addition of CFs into the matrix, $2 \mathrm{wt} \%\left(v_{f}=0.025\right)$.

Fig. 7 also reports the content of $\mathrm{Mg}$ (main alloying constituent) and $\mathrm{Cu}$ (deriving from the fibre coating) for different volume fractions of $\mathrm{CFs}$. Mg and $\mathrm{Cu}$ elements have a detrimental effect on the thermal conductivity of the matrix $\left(K_{m}\right)$, therefore any increase on the content of these elements will decrease this property substantially [19]. The Mg content is relatively constant for the different composites. Whereas, the $\mathrm{Cu}$ content increases proportionally with the rise of $\mathrm{CF}$ content reaching a maximum of $2.04 \mathrm{wt} \%$ for the $\mathrm{C} 2$ composite sample. This indicates that despite the random orientation of the fibres in the matrix, the thermal contribution from the fibres is starting to overcome the negative effect of the $\mathrm{Cu}$.

\subsection{Equal channel angular extrusion (ECAE)}

After 4 passes, the random orientation of the reinforcing fibres of the C1.5 rheocast composites (Fig. 8(a)) is changed to a microstructure with a high degree of alignment where the fibre alignment direction was measured to be at an angle in the range of $8.51^{\circ}-9.32^{\circ}$ as shown in Fig. 8(b).

The angle was reduced after 6 passes to around $2.69^{\circ}$ with improved microstructural alignment (Fig. 8(c)). The Z contrast micrograph of the composite after 6 passes shown in Fig. 8(d) reveals a high degree of CF (dark) and intermetallic (bright) alignment. Generally, the higher the number of ECAE passes the lower the angle (øED-AD) between the extrusion direction (ED) and the fibre alignment direction (AD). In the ideal simple shear condition, the microstructural elongation direction is at an angle of $\beta_{n}$ to the extrusion direction after $n$ passes:

$\beta_{n}=\arctan \Gamma^{-1}$

where $\Gamma$ is the total shear strain after $\mathrm{n}$ passes:

$\Gamma=2 n \cot \phi$

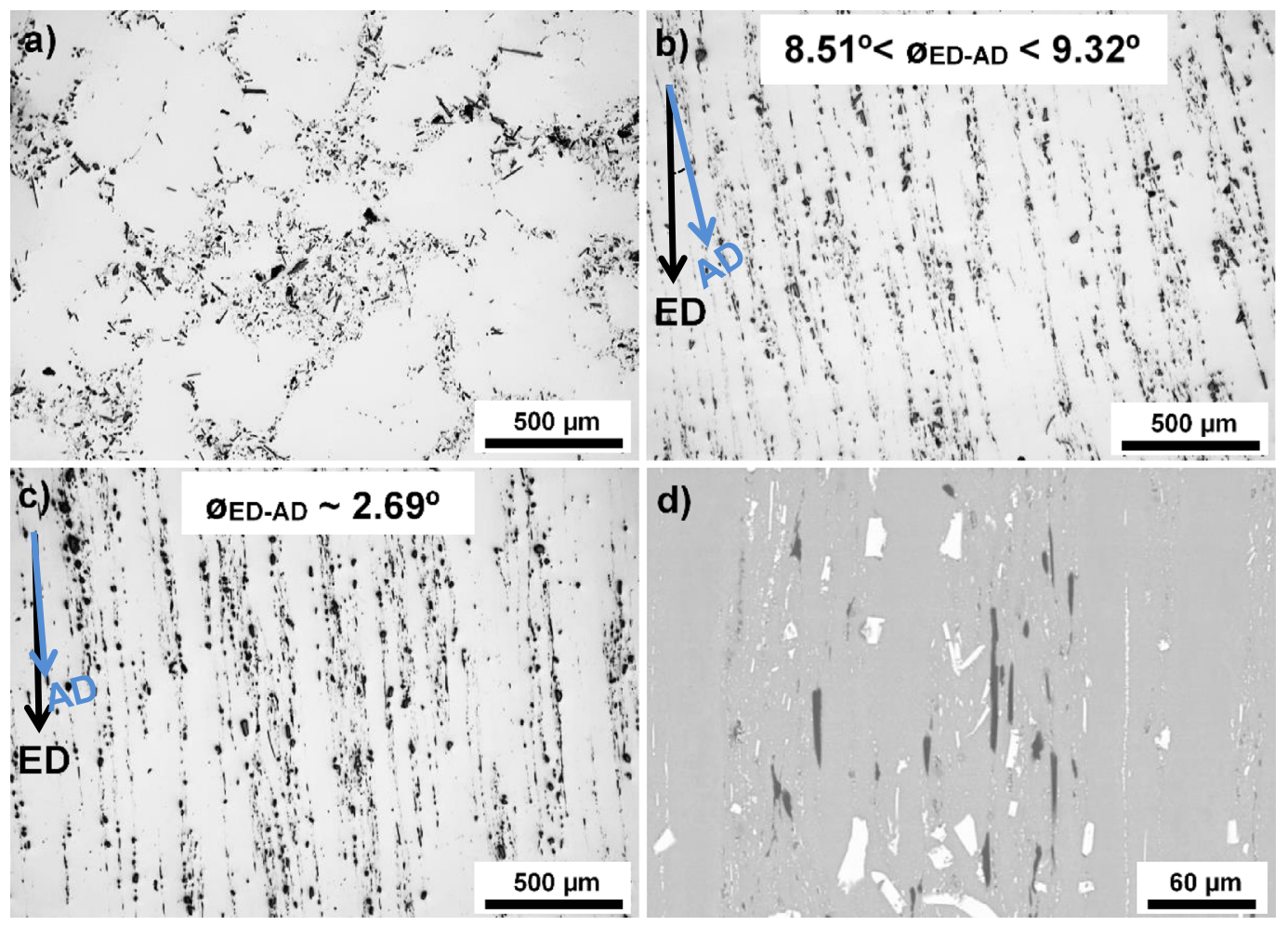

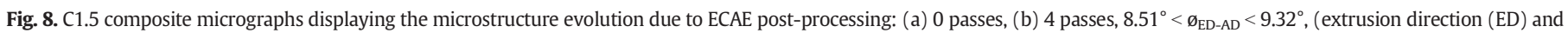
alignment direction (AD), (c) 6 passes, $\emptyset_{\mathrm{ED}-\mathrm{AD}} \sim 2.69^{\circ}$, and (d) 6 passes BSE image displaying a high alignment between CFs (dark) and intermetallics (bright) within the Al matrix. 

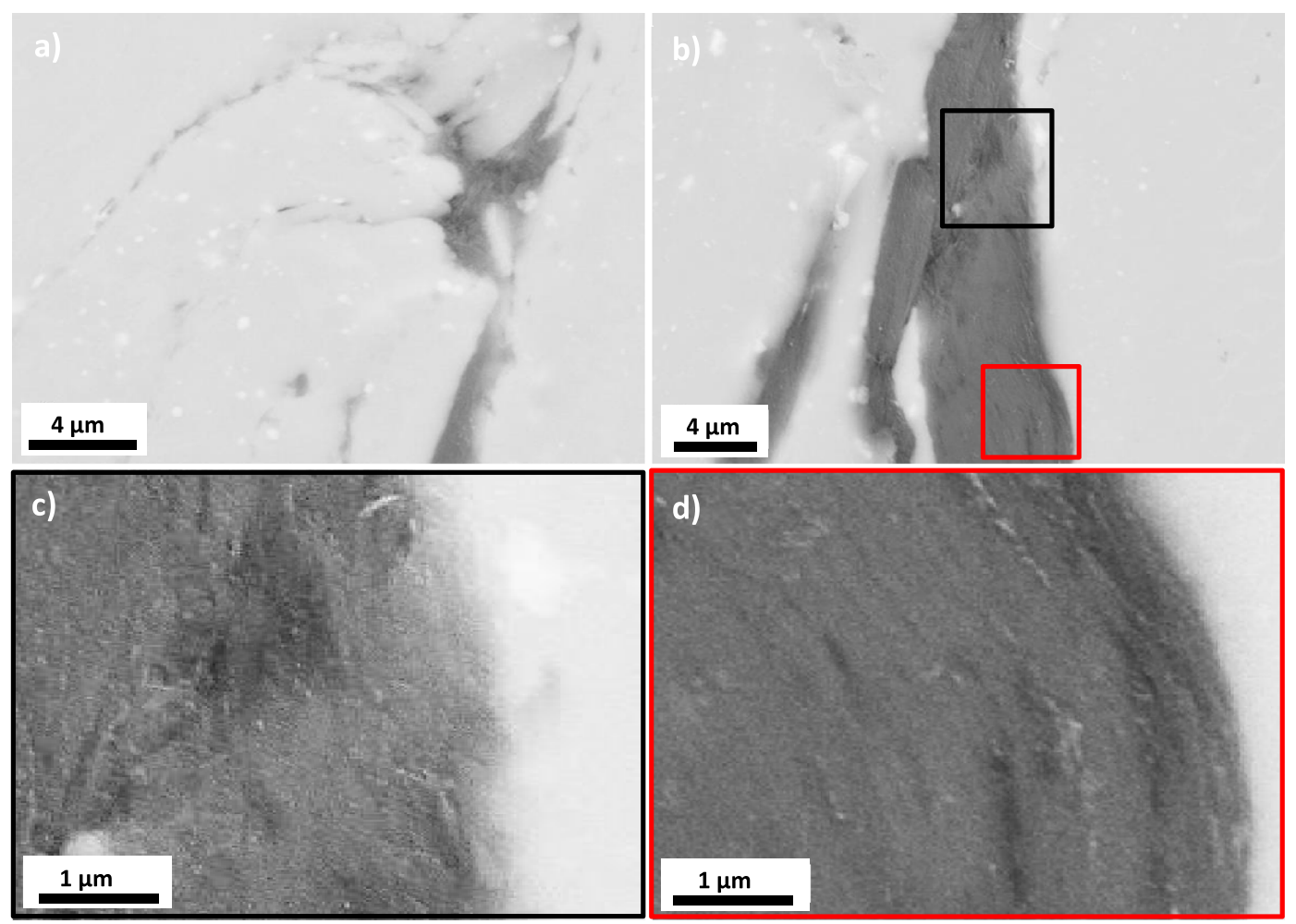

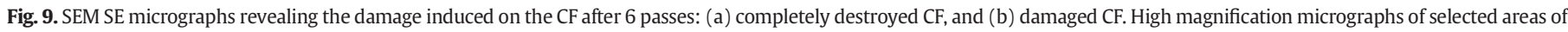
the damaged CF where its structure has fractured (c) or aligned (d) in the alignment direction.

where $\phi$ is the half extrusion angle and $n$ is the total number of ECAE passes. According to Eq. (1), the microstructural elongation angles after 4 and 6 passes are $12.3^{\circ}$ and $8.3^{\circ}$ respectively, which are close to the experimentally measured values. ECAE has been used for grain refinement but has also been successfully used for the consolidation of porous materials [20].

In the present work, ECAE successfully improved the composite density as the porosity fraction was already reduced from $3 \%$ to $0.03 \%$ for the $\mathrm{C} 1.5$ composite after 4 passes. Nevertheless, despite the successful production of a highly aligned $\mathrm{Al} / \mathrm{Cu}-\mathrm{CFs}$ composite microstructure, it is crucial that the ECAE processing does not cause substantial damages to the CFs as this may reduce the fibres thermal conductivity capability.

As expected ECAE resulted in the damaging of the fibres and the extent of damage is dependent on the fibres initial orientation prior to deformation. In the worst case scenario, when there is a $90^{\circ}$ angle between the orientation of the CFs and the extrusion direction, the fibre is nearly completely destroyed as shown in Fig. 9(a). Other fibres have less damage (Fig. 9(b)) and the analysis at higher magnification reveals that fracture (Fig. 9(c)) and alignment (Fig. 9(d)) can happen in the same fibre.

The thermal conductivity results for the C1.5 composite (Fig. 10) show that the deformation induced to align the fibres results in a continuous in-plane (parallel to ED) thermal conductivity $\left(K_{c, 1}\right)$ improvement as the number of passes increases, reaching the maximum value of $K_{c, C 1.5,6 p, 1}=153.7 \pm 4.6 \mathrm{~W} \mathrm{~m}^{-1} \mathrm{~K}^{-1}$ after 6 passes. This is an increment of $19.6 \%$ when compared to the rheocast material (0 passes).

The improvement in thermal conductivity by fibre alignment was observed despite the damage induced on the fibres (Fig. 9) and the overall microstructure deformation, which both have a detrimental contribution with respect to the composite thermal conductivity. The composite out-of-plane (perpendicular to ED) thermal conductivity $\left(K_{c, 2}\right)$ increases marginally, reaching its peak after 4 passes, $K_{c, c 1.5,4 p, 2}$ $=133.4 \pm 4 \mathrm{~W} \mathrm{~m}^{-1} \mathrm{~K}^{-1}$ and decreasing to $K_{c, c 1.5,6 p, 2}=131.6 \pm$ $3.9 \mathrm{~W} \mathrm{~m}^{-1} \mathrm{~K}^{-1}$ after 6 passes. Nevertheless, the thermal conductivity of the $\mathrm{C} 1.5$ composite after ECAE is always higher than for the rheocast C1.5 composite, $K_{c, ~ C 1.5,0 p}=128.5 \pm 3.9 \mathrm{~W} \mathrm{~m}^{-1} \mathrm{~K}^{-1}$. The increment in thermal conductivity is believed to be due to the combined effect of porosity closure, fibre alignment and an intimate contact of the matrix with MgO-free CFs surfaces.

\section{Discussion}

The thermal conductivity comparison was performed according to two circumstances referred to as the "theoretical" and "corrected" conditions. For the former it is assumed that the fibres diameter and length are constant; however, this is not real as the rheocasting + ECAE method does break and reduce the fibres size. It is also assumed that

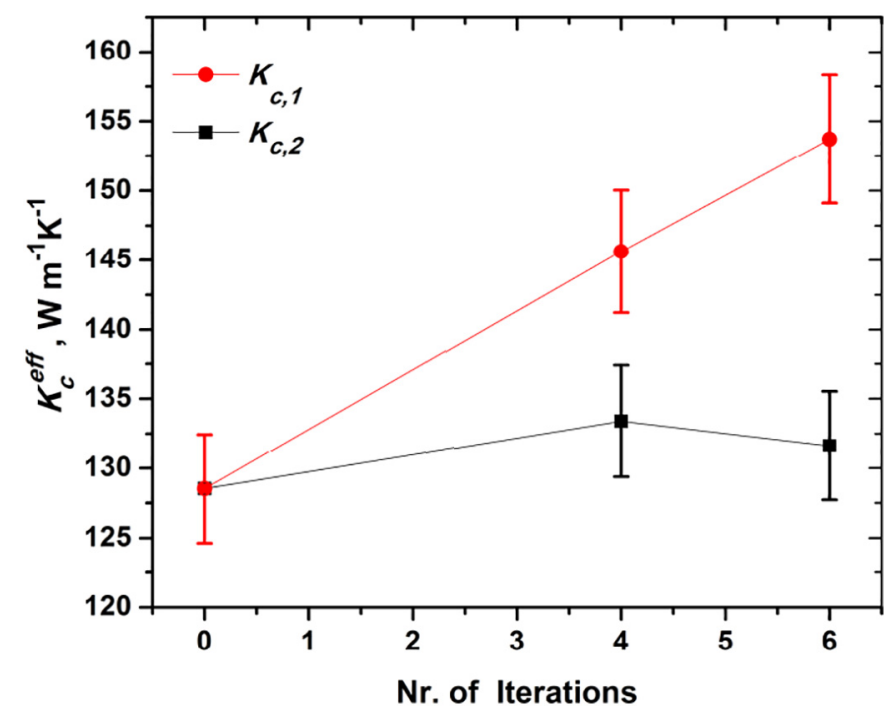

Fig. 10. Effective thermal conductivity of the $\mathrm{C} 1.5$ (1.5 wt\% $\mathrm{CFs}$ ) Al-3Mg/Cu-CF composite in the direction parallel to $\mathrm{ED}\left(K_{c, 1}\right)$ and in the direction perpendicular to $\operatorname{ED}\left(K_{c, 2}\right)$ as a function of the number of ECAE passes. 

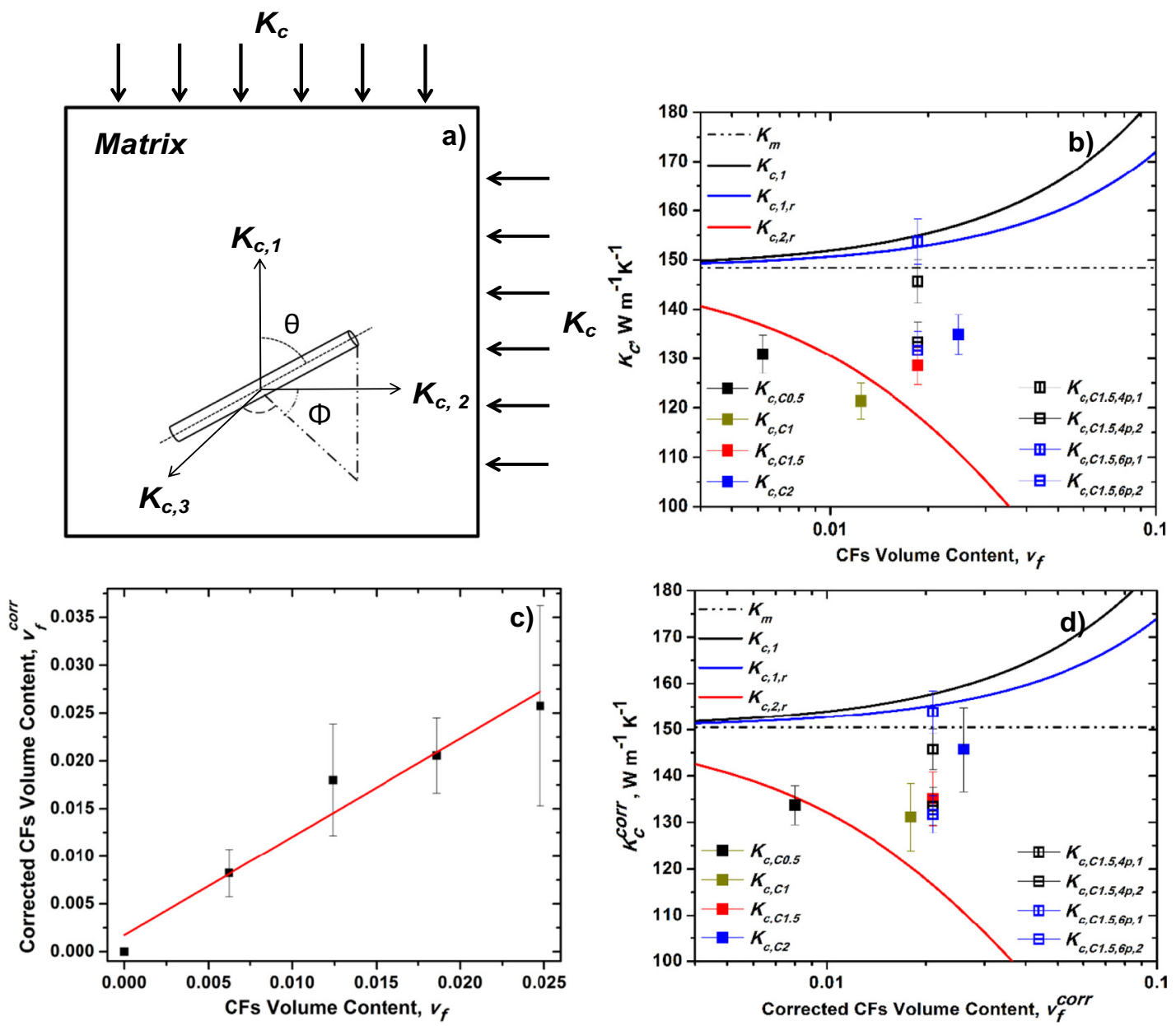

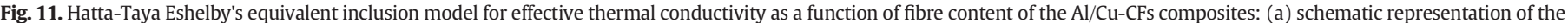

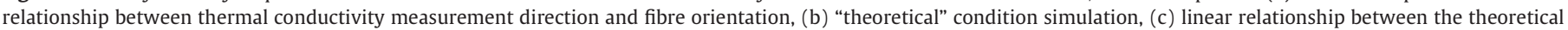
$v_{f}$ and corrected $v_{f}^{\text {corr }}$ CFs volume fraction content, and (d) "corrected" condition simulation accounting for the porosity and CFs $v_{f}^{\text {corr }}$ content.

no porosity is present, the fibres are individually and homogeneously dispersed throughout the metal matrix and their volume fraction $\left(v_{f}\right)$ is the same as initially introduced during processing. Furthermore, the presence of interfacial barriers is not accounted for, assuming that the $\mathrm{Cu}$ coating on the fibres completely dissolves in the Al matrix. In the case of the corrected condition scenario, all the parameters used in the theoretical conditions are applied. However, the effect of porosity volume faction $(\varphi)$ and the real or corrected CFs volume fraction $\left(v_{f}^{\text {corr }}\right)$, which were obtained using the surface area analysis technique, are accounted for. It is worth mentioning that the effect of the increasing $\mathrm{Cu}$ content (Fig. 7) on the thermal conductivity of the composite was not taken into account in the modelling.

Fig. 11 shows the experimental thermal conductivity of the composites $K_{c}$ processed via rheocasting and rheocasting + ECAE as a function of CFs content and the Hatta-Taya's model boundary conditions [21,22].

Fig. 11(a) illustrates the relationship between the thermal conductivity measurement direction and fibre orientation.
$K_{c, 1}$ assumes that the fibres in the plane 1-2 are all aligned in the thermal conductivity acquisition direction $\left(K_{c, 1}\right)$, in other words $\theta=$ $0^{\circ}$ (unidirectional). $K_{c, 1, r}$ assumes that the fibres are aligned in the plane $1-2$, parallel to the thermal conductivity measurement direction $\left(K_{c, 1}\right)$, where $\Phi=0^{\circ}$ but the angle between the $K_{c, 1}$ and the fibre orientation is random $0^{\circ} \leq \theta \leq 90^{\circ} . K_{c, 2}$ simulates the thermal conductivity of the composite when the fibres are perpendicularly aligned to the thermal conductivity acquisition direction, where $\Phi=90^{\circ}$ and $\theta=$ $90^{\circ}$, whereas, $K_{c, 2, r}$ accounts for $\Phi=90^{\circ}$, however the fibres are randomly aligned in the plane $1-3,0^{\circ} \leq \theta \leq 90^{\circ}$. Nevertheless, in this case $K_{c, 2}=K_{c, 2, r}$. The modelling parameters used in the Hatta-Taya Eshelby's equivalent inclusion model are given in Table 4 and plotted in Fig. 11.

Ideally, due to the CFs anisotropic thermal behaviour, the composites produced via rheocasting should have $K_{c}$ between the in-plane $K_{c}$, ${ }_{1}$, (also referred to as the higher boundary) and out-of-plane $K_{c, 2, r}$, (lower boundary). Whereas, in the case of the composites processed

Table 4

Modelling parameters for the $\mathrm{Al} / \mathrm{Cu}-\mathrm{CFs}$ composites.

\begin{tabular}{|c|c|c|c|c|c|c|}
\hline \multicolumn{2}{|c|}{ Matrix (Al-3Mg) } & \multicolumn{5}{|l|}{ Carbon fibres } \\
\hline $\begin{array}{l}K_{m} \\
\left(\mathrm{~W} \mathrm{~m}^{-1} \mathrm{~K}^{-1}\right)\end{array}$ & $\begin{array}{l}\rho_{m} \\
\left(\mathrm{~g} \mathrm{~cm}^{-3}\right)\end{array}$ & $\begin{array}{l}K_{f, 1} \\
\left(\mathrm{~W} \mathrm{~m} \mathrm{~m}^{-1} \mathrm{~K}^{-1}\right)\end{array}$ & $\begin{array}{l}K_{f, 2} \\
\left(\mathrm{~W} \mathrm{~m}^{-1} \mathrm{~K}^{-1}\right)\end{array}$ & $\begin{array}{l}l_{f} \\
(\mu \mathrm{m})\end{array}$ & $\begin{array}{l}d_{f} \\
(\mu \mathrm{m})\end{array}$ & $\begin{array}{l}\rho_{f} \\
\left(\mathrm{~g} \mathrm{~cm}^{-3}\right)\end{array}$ \\
\hline $148.4 \pm 4.6$ & 2.65 & 500 & 10 & $285.41 \pm 177.27$ & $8.79 \pm 2.03$ & 2.23 \\
\hline
\end{tabular}


by rheocasting + ECAE, $K_{c}$ should be close to the higher boundary and lower boundary values due to the induced fibre alignment. Fig. 11 (b) shows the comparison of the Hatta-Taya Eshelby's equivalent inclusion model for the theoretical condition with the experimental thermal conductivity of the produced $\mathrm{Al} / \mathrm{Cu}-\mathrm{CFs}$ composites. The $\mathrm{C} 0.5$ and $\mathrm{C} 1$ composite values $K_{c, \text { co.5 }}$ and $K_{c, c 1}$, respectively, do not lie between the boundaries, in fact they are lower than the lower boundary.

The experimental value $K_{c, c 1.5}$ lies between the boundary conditions values, however, still close to the lower limit $K_{c, c 1.5,2, r}$.

Conversely, the composite sample $\mathrm{C} 1.5$ processed by the ECAE technique shows good agreement with Eshelby's model. As the number of ECAE passes increases the experimental in-plane (1) and out-of-plane (2) thermal conductivity values become closer to the higher and lower boundaries. After 4 passes the experimental in-plane thermal conductivity $\left(K_{c, C 1.5,4 p, 1}\right)$ increases in comparison to the rheocast C1.5 composite $\left(K_{c, c 1.5}\right)$ but it is still below the value predicted by the model $\left(K_{c, c 1.5,1}\right.$ and $\left.K_{c, c 1.5,1, r}\right)$. Nevertheless, the value after 6 passes $\left(K_{c, c 1.5,6 p, 1}\right)$ is in good agreement with the model for the in-plane condition and proves that fibre alignment does improve composite thermal conductivity. Despite the decreasing $K_{c}$ with increasing number of ECAE passes, the experimental out-of-plane $K_{c, C 1.5,4 p, 2}$ and $K_{c, C 1.5,6 p, 2}$ thermal conductivity values are still above the $K_{c, c 1.5,2, r}$ value obtained by the Eshelby model, $+15.6 \mathrm{~W} \mathrm{~m}^{-1} \mathrm{~K}^{-1}$ and $+13.8 \mathrm{~W} \mathrm{~m}^{-1} \mathrm{~K}^{-1}$ for the ECAE composites after 4 and 6 passes, respectively. Finally, the experimental thermal conductivity of the $\mathrm{C} 2$ composite sample is $K_{c, \mathrm{c} 2}=$ $134.9 \pm 4.1 \mathrm{~W} \mathrm{~m}^{-1} \mathrm{~K}^{-1}$, whilst the modelling gives a value of $K_{c, C 2,1}$ $=157.2 \mathrm{~W} \mathrm{~m}^{-1} \mathrm{~K}^{-1}, K_{c, c 2,1, r}=154.2 \mathrm{~W} \mathrm{~m}^{-1} \mathrm{~K}^{-1}$ and $K_{c, c 2,2, r}=$ $110.6 \mathrm{~W} \mathrm{~m}^{-1} \mathrm{~K}^{-1}$. In this case, the experimental value lies between the lower, $K_{c, c 2,2, r}$, and the higher, $K_{c, c 2,1}$, boundary conditions.

Fig. 11(c) shows the linear relationship between the theoretical $\left(v_{f}\right)$ and real/corrected $\left(v_{f}^{\text {corr }}\right) \mathrm{CFs} v_{f}$ and proves that, in this case, using the image analysis method to determine the real $v_{f}$ of the fibres is viable. Fig. 11(d) shows the comparison of $K_{c}$ from the Al/Cu-CFs composites with the Eshelby's equivalent inclusion model for effective thermal conductivity. However, in this case the "corrected" condition is applied and thus the "corrected" thermal conductivity of the composite $\left(K_{c}^{\text {corr }}\right)$ was calculated using Eq. (3) [6] to remove the effect of the porosity volume fraction $(\varphi)$ resulting in a general increase of the thermal conductivity.

$K_{c}^{\text {corr }}=K_{c} /(1-\varphi)^{n}$

For the corrected condition, the C0.5 composite experimental value $K_{c, C 0.5}^{\text {corr }}$ does not lie between the boundary conditions, however it is much closer to the lower boundary $K_{c, C O .5,2, r}^{c o r r}$. The correction factor brought the composite experimental value of $\mathrm{C} 1, K_{c, \mathrm{C} 1}^{\mathrm{corr}}$, between the boundary condition values. C1.5 composite with $\varphi_{C 1.5}=0.03 \pm 0.01$ and $v_{f, C 1.5}^{\text {corr }}=0.021 \pm 0.004$ has $K_{c, C 1.5}^{\text {corr }}=135.1 \pm 5.8 \mathrm{~W} \mathrm{~m}^{-1} \mathrm{~K}^{-1}$, whereas the modelling for the corrected condition predicts in-plane and out-of-plane values of: $K_{c, C 1.5,1}^{c o r r}=157.8 \mathrm{~W} \mathrm{~m}^{-1} \mathrm{~K}^{-1}, K_{c, C 1,1, r}^{c o r r}=$ $155.3 \mathrm{~W} \mathrm{~m}^{-1} \mathrm{~K}^{-1}$ and $K_{c, C 1,2, r}^{\text {corr }}=116.5 \mathrm{~W} \mathrm{~m}^{-1} \mathrm{~K}^{-1}$. Therefore the corrected composite $\mathrm{C} 1.5$ thermal conductivity experimental value also lies between the boundary conditions values. The experimental thermal conductivity of the $\mathrm{C} 1.5$ composite processed by the ECAE technique using the corrected condition is also in good agreement with the Eshelby's model. After 4 passes, despite the correction factor, the composite thermal conductivity is still below the higher boundary values predicted by the model. The value after 6 passes shows good agreement with the model in the in-plane direction. The respective simulated outof-plane corrected thermal conductivity is $K_{c,}^{\text {corr }} \mathrm{C1.5,2} \quad r=$ $116.5 \mathrm{~W} \mathrm{~m}^{-1} \mathrm{~K}^{-1}$ and shows that as for the theoretical condition the out-of-plane corrected experimental values are again above the lower boundary value given by the model, $+17 \mathrm{~W} \mathrm{~m}^{-1} \mathrm{~K}^{-1}$ and $+15.2 \mathrm{~W} \mathrm{~m}^{-1} \mathrm{~K}^{-1}$ for the ECAE composites after 4 and 6 passes, respectively. As expected, the corrected experimental thermal conductivity of the composite $\mathrm{C} 2\left(K_{c, 2}^{\text {corr }}\right)$, lies between the boundary conditions values.
Since rheocasting can only disperse fibres randomly (in any orientation/direction) in the matrix, it would be expected that the rheocast composites would not be in agreement with the model but rather have values in between the higher and lower boundaries. From Fig. 11 (d), this is the case for all the rheocast composites with the exception of the C0.5 sample, most likely due to the formation of fibre agglomerates. The thermal conductivity modelling of the composite fits better with the experimental results for the corrected condition rather than the theoretical condition demonstrating the importance of porosity content and the real volume fraction of the fibres present on the composite thermal conductivity.

After post-processing via ECAE the thermal conductivity in the inplane direction greatly improved reaching the maximum thermal conductivity after 6 passes $\left(C 1.5_{6 \mathrm{p}, 1}\right)$. Silvain et al. [23] reported the production of AMCs via hot pressing using pitch-based CFs from the same manufacturer as those used in this study. They found that a $\mathrm{CF}$ volume content $v_{f}=0.1$, only had an increase of $\Delta K_{c, 1}=9 \mathrm{~W} \mathrm{~m}^{-1} \mathrm{~K}^{-1}$ ( $4.6 \%)$. The composite post-processed via ECAE in this study has $\Delta K_{c}$, c1.56p, $1=25.3 \mathrm{~W} \mathrm{~m}^{-1} \mathrm{~K}^{-1}$, despite having 5 times less fibres. The difference observed is most likely due to the fact that hot pressing has lower fibre alignment capability.

ECAE is a severe plastic deformation (SPD) process that produces ultra-fine grain (UFG) materials [24]. After ECAE the composite grain size was reduced, decreasing atomic order and increasing grain boundary density and dislocations. These factors reduce the electron mean free path (i.e. they decrease the thermal conductivity of the metallic matrix). However, the deformation induced, other than aligning, also breaks fibres, and causes damage as illustrated in Fig. 9. The damage reduces the phonon mean free path (i.e. the fibres heat conduction mechanism), resulting in phonon scatter. Despite all these factors, the experimental results indicate that processing $\mathrm{Al} / \mathrm{CF}$ composites via rheocasting followed by ECAE seems to be viable for producing composites with an improved thermal conductivity.

\section{Conclusions}

The study demonstrates that rheocasting is efficient in introducing and dispersing the $\mathrm{Cu}$-coated $\mathrm{CFs}$ ( $\mathrm{Cu}-\mathrm{CFs}$ ) within the $\mathrm{Al} 3 \mathrm{Mg}$ matrix. However, the porosity content of the composites produced increases up to $5 \%$ for a carbon fibre content of up to $2 \mathrm{wt} \%$. The subsequent processing of the $\mathrm{Al} / \mathrm{Cu}-\mathrm{CFs}$ composites ( $\mathrm{C} 1.5$ composite samples) using the ECAE method shows good efficiency in removing porosity and achieving a high degree of fibre alignment with good fibre matrix interface surface consolidation. The severe deformation characteristic of the ECAE technique induces considerable damage on the fibres. Nonetheless, after 6 passes of ECAE the composite thermal conductivity improves 20\% with respect to the rheocast composite. This improvement is believed to be due to porosity reduction, fibre alignment and forced intimate contact of clean carbon fibres surfaces with the matrix. Further studies are necessary to understand the contribution of each factor to the composite thermal conductivity. The experimental thermal conductivity of C1.5 composite sample post-processed by ECAE shows good agreement with Eshelby's model demonstrating the viability of the rheocasting + ECAE processing method for producing composites with improved thermal conductivity.

\section{Acknowledgements}

The author wishes to acknowledge the support from the Korea Institute of Industrial Technology (KITECH), and the Experimental Techniques Centre (ETC) at Brunel University London.

\section{Data availability statement}

The raw/processed data required to reproduce these findings cannot be shared at this time due to legal or ethical reasons. 


\section{References}

[1] J.P. Davim, Metal Matrix Composites: Materials, Manufacturing and Engineering Walter de Gruyter GmbH \& Co KG, 2014

[2] C.H. Zweben, New material options for light-emitting diode packaging, Proc. SPIE 5366 (2004) 173-182.

[3] S. Liu, X. Luo, LED Packaging for Lighting Applications: Design, Manufacturing, and Testing, John Wiley \& Sons, 2011.

[4] C. Zweben, Advanced thermal management materials for electronics and photonics, Adv. Microelectron. 37 (2010) 14-19.

[5] L. Lindsay, D.A. Broido, T.L. Reinecke, First-principles determination of ultrahigh thermal conductivity of boron arsenide: a competitor for diamond? Phys. Rev. Lett. 111 (2013).

[6] A. Miranda, Characterisation and Processing of Carbon Based Reinforced Al-MMCs for Thermal Management Applications, PhD Thesis Brunel University, 2016.

[7] D.D.L. Chung, Carbon Fiber Composites, Butterworth-Heinemann, 1994.

[8] C. Zweben, Advances in composite materials for thermal management in electronic packaging, JOM 50 (1998) 47-51.

[9] E.L. Paul, V.A. Atiemo-Obeng, S.M. Kresta, Handbook of Industrial Mixing: Science and Practice, John Wiley \& Sons, 2004.

[10] D.B. Spencer, R. Mehrabian, M.C. Flemings, Rheological behavior of Sn-15 pct Pb in the crystallization range, Metall. Trans. A 3 (1972) 1925-1932.

[11] G. Hirt, R. Kopp, Thixoforming: Semi-solid Metal Processing, Wiley-VCH, 2009.

[12] P.K. Ghosh, S. Ray, Fabrication and properties of compocast aluminium-alumina particulate composite, Indian J. Technol. 26 (1988) 83-94.
[13] P.N. Bindumadhavan, et al., Effect of particle-porosity clusters on tribological behavior of cast aluminum alloy A356-SiCp metal matrix composites, Mater. Sci. Eng. A 315 (2001) 217-226.

[14] S.N. Aqida, M.I. Ghazali, J. Hashim, Effect of porosity on mechanical properties of metal matrix composite: an overview, J. Technol. 40 (2012) 17-32.

[15] S.N. Ahmad, The effects of porosity on mechanical properties of cast discontinuous reinforced metal-matrix composite, J. Compos. Mater. 39 (2005) 451-466.

[16] L. Vitos, A.V. Ruban, H.L. Skriver, J. Kollar, The surface energy of metals, Surf. Sci. 411 (1998) 186-202.

[17] S. Nuriel, L. Liu, A.H. Barber, H.D. Wagner, Direct measurement of multiwall nanotube surface tension, Chem. Phys. Lett. 404 (2005) 263-266.

[18] B.C. Pai, G. Ramani, R.M. Pillai, K.G. Satyanarayana, Role of magnesium in cast aluminium alloy matrix composites, J. Mater. Sci. 30 (1995) 1903-1911.

[19] C.Y. Ho, M.W. Ackerman, K.Y. Wu, S.G. Oh, T.N. Havill, Thermal conductivity of ten selected binary alloy systems, J. Phys. Chem. Ref. Data 7 (1978) 959-1178.

[20] K. Xia, Consolidation of particles by severe plastic deformation: mechanism and applications in processing bulk ultrafine and nanostructured alloys and composites, Adv. Eng. Mater. 12 (2010) 724-729.

[21] H. Hatta, M. Taya, Effective thermal conductivity of a misoriented short fiber composite, J. Appl. Phys. 58 (1985) 2478.

[22] H. Hatta, M. Taya, F.A. Kulacki, J.F. Harder, Thermal diffusivities of composites with various types of filler, J. Compos. Mater. 26 (1992) 612-625.

[23] J.-F. Silvain, A. Veillère, Y. Lu, Copper-carbon and aluminum-carbon composites fabricated by powder metallurgy processes, J. Phys. Conf. Ser. 525 (12015) (2014).

[24] E.A. Prokofiev, A.M.J. Junior, W.J. Botta, R.Z. Valiev, Development of UltrafineGrained Metals By Equal-Channel Angular Pressing. Comp. Mat. Proc, Elsevier, 2014. 